\title{
Moving target: shifting the focus to pulmonary sarcoidosis as an autoimmune spectrum disorder
}

\author{
Ylva Kaiser (1), Anders Eklund and Johan Grunewald
}

Affiliation: Respiratory Medicine Unit, Dept of Medicine, Solna and Center for Molecular Medicine, Karolinska Institutet and Karolinska University Hospital Solna, Stockholm, Sweden.

Correspondence: Ylva Kaiser, Lung Research Lab, BioClinicum J7:30, Dept of Medicine, Solna, Karolinska Institutet and Karolinska University Hospital Solna, 17176 Stockholm, Sweden. E-mail: ylva.kaiserlaki.se

@ERSpublications

This review highlights the emphasis of recent years on the clinical and immunological heterogeneity of sarcoidosis, the role of immune hyperactivity and autoimmunity in disease pathogenesis, and newly proposed disease-triggering antigens http://ow.ly/tfFi30oo9yB

Cite this article as: Kaiser Y, Eklund A, Grunewald J. Moving target: shifting the focus to pulmonary sarcoidosis as an autoimmune spectrum disorder. Eur Respir J 2019; 54: 1802153 [https://doi.org/10.1183/ 13993003.021532018].

ABSTRACT Despite more than a century of research, the causative agent(s) in sarcoidosis, a heterogeneous granulomatous disorder mainly affecting the lungs, remain(s) elusive. Following identification of genetic factors underlying different clinical phenotypes, increased understanding of CD $4^{+}$ T-cell immunology, which is believed to be central to sarcoid pathogenesis, as well as the role of B-cells and other cells bridging innate and adaptive immunity, contributes to novel insights into the mechanistic pathways influencing disease resolution or chronicity. Hopefully, new perspectives and state-of-the-art technology will help to shed light on the still-elusive enigma of sarcoid aetiology. This perspective article highlights a number of recent advances in the search for antigenic targets in sarcoidosis, as well as the main arguments for sarcoidosis as a spectrum of autoimmune conditions, either as a result of an external (microbial) trigger and/or due to defective control mechanisms regulating the balance between $\mathrm{T}$-cell activation and inhibition. 


\section{Introduction}

Sarcoidosis is a granulomatous multisystem disorder of unknown aetiology, which primarily manifests in the lungs [1, 2]. Over the years, postulated causes of disease have included infectious agents [3], e.g. Mycobacterium tuberculosis [4,5] and Propionibacterium acnes [6-8], or remnants thereof, exposure to environmental irritants [9], protein misfolding [10] or, most recently, autoimmunity [11, 12]. Still, more than 140 years after its first observation, and decades of clinical, epidemiological, genetic and immunological research, the causative agent(s) have yet to be identified.

In recent years, our group and others have contributed to increased understanding of $\mathrm{CD} 4^{+} \mathrm{T}$-cell immunology in sarcoidosis, which has been shown to be far more complex than initially appreciated. Moreover, other cell types previously more or less neglected in sarcoidosis research, such as B-cells, CD8 ${ }^{+}$ cytotoxic T-cells (CTLs), dendritic cells (DCs), natural killer cells and natural killer T-cells, are gradually becoming focal points in unravelling the mechanistic pathways influencing granuloma resolution and persistence. In parallel, steady progress has been made in the continuously ongoing, and thus far inconclusive, quest for the "sarcoidosis antigen(s)". Hopefully, state-of-the-art technology and emerging insights into T-cell and B-cell receptor repertoires will shed light on the still-elusive enigma of sarcoid pathogenesis.

\section{Clinical and immunological features of sarcoidosis disease phenotypes}

Identification of disease-triggering factors is complicated by the heterogeneity in sarcoidosis presentation; on one hand, the acute form Löfgren's syndrome (LS) is characterised by sudden onset, fever and distinct clinical symptoms such as bilateral hilar lymphadenopathy, erythema nodosum and/or ankle arthritis, but also a usually self-limiting disease course. On the other hand, so-called "non-LS" sarcoidosis comprises a much more diverse group, commonly distinguished from LS by insidious onset, slow progression and a higher risk of developing chronic disease and pulmonary fibrosis. Importantly, as diagnostic assessment is made primarily on clinical criteria, the molecular mechanisms underlying development of different disease phenotypes remain unknown.

\section{The Th-1/Th-17 paradigm in sarcoidosis}

While initially considered to be primarily a T-helper (Th) type 1-driven disorder, due to the high levels of interferon (IFN)- $\gamma$, inerleukin (IL)-2 and tumour necrosis factor- $\alpha$ produced by bronchoalveolar lavage fluid (BALF) T-cells and alveolar macrophages [13, 14], presence of Th-1-skewing cytokines IL-12 and IL-18 [15-17], as well as the high T-cell expression of chemokine receptors CXCR3 and CCR5 [18], recent years have seen a shift in the understanding of sarcoidosis as a Th-1/Th-17-mediated disease. In several individual studies [19-23], a majority of $\mathrm{CD}^{+} \mathrm{T}$-cells in sarcoidosis patients and healthy individuals have been found to express both canonical Th-1 chemokine receptor CXCR3 and Th-17-associated CCR6 in BALF, but not in peripheral blood. Moreover, simultaneous expression of transcriptional regulators T-bet (Th-1) and ROR $\gamma \mathrm{T}$ (Th-17) has been demonstrated in the lung, with "Th-1/Th-17" hybrid cells constituting $\sim 25 \%$ in healthy subjects [19]. In the sarcoid, and especially the LS lung, this percentage was markedly increased, and patients with non-chronic disease were found to present with higher frequencies of T-bet ${ }^{+} \mathrm{ROR} \gamma \mathrm{T}^{+} \mathrm{CD} 4^{+} \mathrm{T}$-cells compared to patients with chronic disease [19]. The discrepancy between cellular phenotypes in the lung and the circulation, respectively, suggests that the pulmonary microenvironment actively promotes a Th-1/Th-17 phenotype, even under homeostatic conditions. Furthermore, due to their presence in significant numbers in healthy individuals, Th-1/Th-17 cells do not appear to be inherently "pathogenic" in themselves. For instance, LEXBERG et al. [24] argued that the combined effector repertoires of Th-1 and Th-17 cells might confer a physiological advantage through more efficient orchestration of disease resolution (figure 1). In LS patients, where these cells were most frequent, cytokine production was found to be more varied, with secretion of IL-17A, IL-10, IL-2 and IL-22 in addition to IFN- $\gamma$, which was by far the predominant cytokine in non-LS patients. This finding emphasises that not only the phenotype, but also the functionality of the cell at any given moment is crucial in influencing the outcome of the inflammatory reaction. In Crohn's disease, a granulomatous disorder of the gut, inhibition of IL-17A has been shown not to ameliorate, but rather to exacerbate inflammation [25], suggesting a protective effect of this cytokine and an overlap of Th-1, Th-17 and regulatory T-cell (Treg) functionality of T-cells in mucosal tissues. Both IL-17A and IL-22 have demonstrated protective effects during M. tuberculosis-induced granulomatous inflammation [26], and reduced IL-22 levels have been observed in patients with chronic sarcoidosis and idiopathic pulmonary fibrosis (IPF) [27]. ROR $\gamma \mathrm{T}^{+} \mathrm{CD} 4^{+} \mathrm{T}$-cells are also known to produce IL-10 and act to restrain inflammation [28], implying that the higher IL-10, IL-22 and IL-17A production observed in LS relates to immune regulation and mucosal homeostasis. The recent discovery that so-called "Th-17.1" cells, i.e. cells that have converted from a classical Th-17 phenotype to express features of both Th-1 and Th-17 cells, including production of either both IL-17A and IFN- $\gamma$, or IFN- $\gamma$ alone [20], are enriched in patients with 


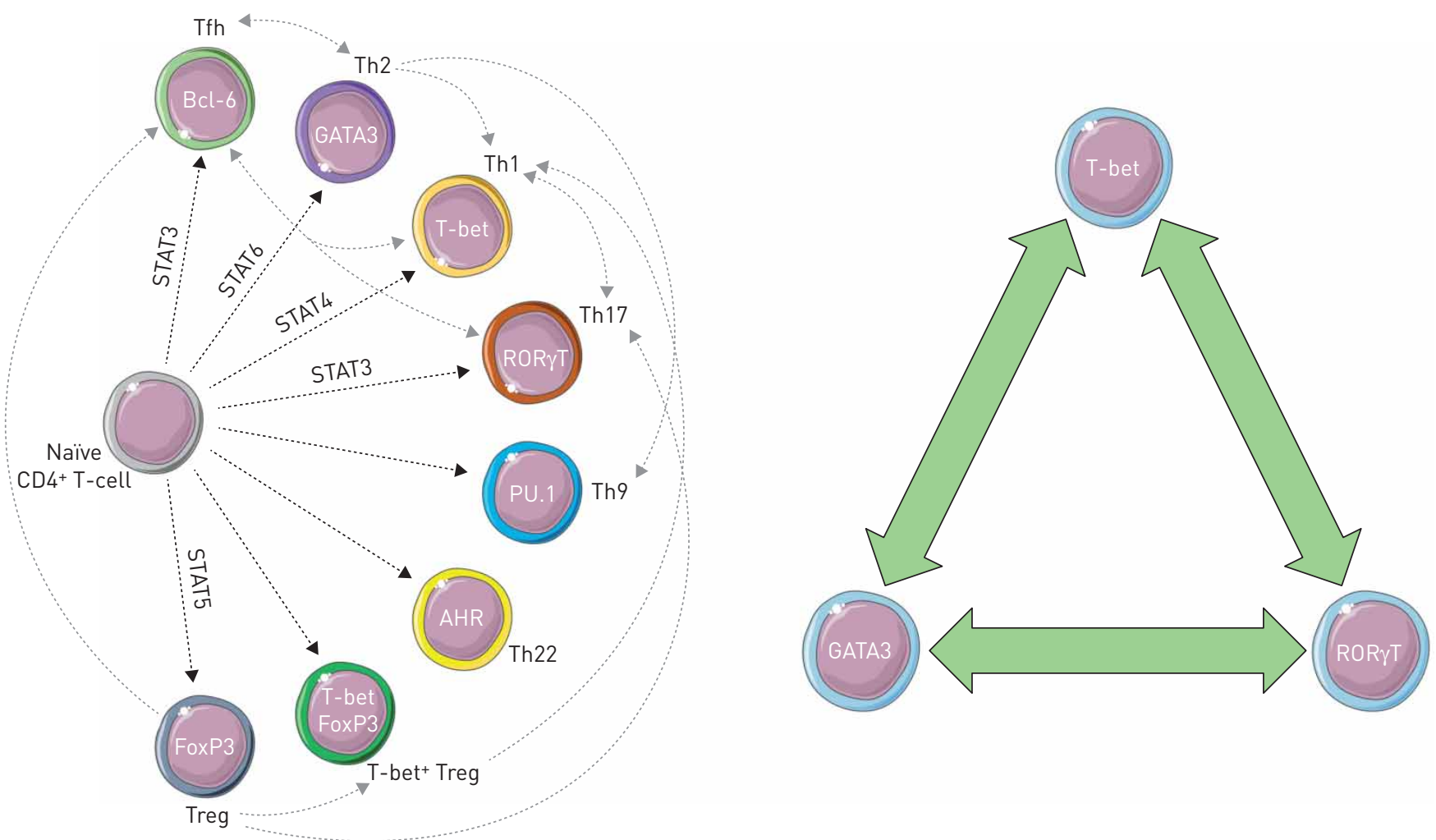

FIGURE $1 \mathrm{CD}^{+}{ }^{+}$T-cell plasticity. Schematic outline of documented T-helper (Th)-1 subsets, along with their "master" transcriptional regulators and postulated pathways of inter-differentiation. The concept of T-cell plasticity infers that rather than entering a state of terminal differentiation, a delicate balance of transcription factor expression (green arrows) ultimately dictates cell fate at a certain, compartment-specific time point. The cell is thereby able to respond to various stimuli and adapt its functionality accordingly depending on the triggering antigen, the tissue microenvironment and timing during the disease course. In the context of sarcoidosis, Th-1/Th-17 hybrid cells are likely to have a tissue-specific surveillance role in the lung under homeostatic conditions, but the presence of disease-associated antigens, combined with underlying genetic factors, drive their functional differentiation into either a more T-bet/ROR $\gamma$ T-balanced (LS) or a T-bet-dominated (non-LS) phenotype that will significantly influence disease outcome. Tfh: follicular T-helper cell.

chronic disease [21] further suggests that IFN- $\gamma$, rather than IL-17A, may be the primary culprit in driving pathogenic processes in the lung [29]. These findings indicate that a combined IL-17A/IFN- $\gamma$ reaction is central to pulmonary immunology, and that this response is enhanced in LS patients, but somehow skewed towards a more aggressive "IFN- $\gamma$ only" phenotype in non-LS patients. Accordingly, it is entirely possible that the Th-1/Th-17-mediated pathogenicity observed in rheumatoid arthritis (RA), multiple sclerosis (MS) and psoriasis, for example [30-34], is primarily driven by excessive IFN- $\gamma$ secretion, and that pro- or anti-inflammatory functions of IL-17A strongly depend on the local tissue microenvironment.

\section{Granulomatous structures and signalling}

Oddly, few, if any, studies have been dedicated explicitly to identifying differences between sarcoidosis phenotypes with regards to the structure or composition of the actual granuloma. As LS is characterised to a large extent by spontaneous resolution, any subtle variability in granuloma formation and maintenance could be of clinical relevance. Using mass cytometry, expression of CD44 on CD4 ${ }^{+} \mathrm{T}$-cells was found to be significantly reduced in LS patients compared to non-LS patients [35]. CD44 mediates adhesion to the endothelium and extracellular matrix and its expression on lymphocytes in pulmonary sarcoidosis, as well as other mucosal disorders such as Crohn's disease, has been speculated to influence their homing and activation, in addition to stimulating macrophage differentiation [36]. Furthermore, elevated levels of soluble CD44 have been demonstrated in conditions with an autoimmune background, including sarcoidosis [37, 38], suggesting involvement in cell-cell communication. Recently, LiNKE et al. [39] discovered increased activity of mechanistic target of rapamycin (mTOR) complexes in sarcoid granulomas of patients with active progressive disease, compared to patients undergoing remission. Intriguingly, mTOR complexes can be inhibited by CD44 blockade [40], suggesting a dual role of CD44 in adhesion as well as signal transduction during granuloma formation and persistence. Consistently reduced CD44 expression on $\mathrm{CD}^{+}$T-cells in LS may thus contribute to an increased tendency of these granulomas to resolve spontaneously. 
Human leukocyte antigen association

While the $H L A-D R B 1^{*} 03$ allele has long been known to associate strongly with LS and a favourable clinical outcome [41], recent genetic studies have revealed striking differences between LS and non-LS, with greater genetic homogeneity among LS patients, and presence of genetic associations not observed in non-LS, and vice versa [42]. The distinction between LS and non-LS is critical in the effort to understand the genetic, immunological and environmental factors contributing to development of chronic disease and resolution. Due to its characteristic clinical presentation and commonly favourable outcome, LS may, in time, even be considered as a separate disease [41].

\section{Sarcoidosis results from immune hyperactivity}

The similarity of sarcoid pathology to that of tuberculosis, characterised by granuloma formation in the lung, initially suggested a common origin and spurred the hypothesis of an infectious agent as a cause of disease. Opinions differ on the exact mechanism, but it has been suggested that sarcoidosis is caused by immune reactivity against incompletely degraded and persisting bacterial antigens, rather than a conventional infection [43]. Mycobacterial and propionibacterial DNA and protein have been identified in sarcoidosis granulomas, and several studies show reactivity of lung-derived T-cells to mycobacterial proteins [4], most frequently mycobacterial catalase-peroxidase ( $\mathrm{mKatG}$ ), the 6-kDa early secretory antigenic target (ESAT-6) and heat-shock proteins [44, 45]. Broad-spectrum anti-mycobacterial therapy has demonstrated positive effects on lung function in chronic sarcoidosis patients [46], although this was primarily attributed to anti-inflammatory effects rather than specific pathogen eradication [47]. In addition, $P$. acnes has been associated particularly with certain manifestations of sarcoidosis such as ocular, cardiac and neurological involvement [48-51], and more recent studies show alterations in the pulmonary microbiome in sarcoid compared to healthy lungs [52]. However, as presence of bacterial DNA [53] and protein [5] have been reported in $\sim 50 \%$ of investigated sarcoidosis patients, and as live mycobacteria have never been identified in or cultured from sarcoid lungs, these findings cannot account for all patients. Likewise, favourable responses to long-term immunosuppressive treatment without emergence of infectious disease argue against intact microbial organisms in sarcoidosis [54]. While a seasonal variation in disease onset [55], particularly for HLA-DRB ${ }^{\star} 03^{+}$LS patients, points to involvement of an infectious agent (or another, non-invasive environmentally derived triggering factor), the accessibility of which fluctuates with the seasons, there is little evidence of an active, ongoing infection in sarcoidosis patients, particularly due to the lack of continuity between studies in which microbial agents are implicated as drivers of disease. Rather, these data together suggest that several forms of pulmonary infection hold the potential to trigger a sarcoid reaction in a genetically susceptible individual, and that ensuing disease is attributed primarily to inherent defects in immune regulation. As discussed later, interference with regulatory mechanisms through checkpoint inhibition, for example, could facilitate a similar setting, serving to shift immune balance in favour of pathogenic processes.

Malfunctions in the innate immune system that result in chronic tissue inflammation are often referred to as "autoinflammatory" conditions, and are typically related to mutations in genes involved in inflammasome activation. In contrast, "autoimmunity" is attributed to a dysregulated adaptive immune response and a disease susceptibility strongly influenced by human leukocyte antigen (HLA)-related genes. Accordingly, activation of the adaptive immune system through recognition of one or several specific extracellular antigenic targets results in a response dominated by $\mathrm{T}$ - and/or B-cells [56]. However, a known antigen is not required for the definition of a disease as autoimmune, and although the situation in sarcoidosis has yet to be strictly defined, the documented presence of clonally expanded $\mathrm{CD} 4^{+} \mathrm{T}$-cells strongly implies autoimmunity rather than autoinflammation.

The concept of sarcoidosis as an autoimmune disease is further supported by the strong HLA connection in LS patients. Moreover, a reported higher prevalence of disease in first-degree relatives [57], as well as a markedly higher risk of developing disease in monozygotic compared to dizygotic twins [58], are suggestive of an imperative hereditary component. In addition, LS patients are generally young, previously healthy and nonsmokers [59]. Self-limiting autoimmune conditions are uncommon, but while LS patients usually resolve spontaneously, it has been shown that in a small group of patients $(<5 \%)$, the disease can relapse later in life $[60,61]$, similar to an autoimmune flare.

In 1941, the Norwegian pathologist Morten Ansgar Kveim first reported the diagnostic use of a skin test based on intradermal injection of a pasteurised saline suspension of sarcoid lymph node tissue [62]. Over the following weeks, most patients with active sarcoidosis, but not healthy controls, would develop granulomatous structures in the skin at the site of injection, which would be verified as sarcoid tissue upon histological examination $[63,64]$. This reaction suggests reactivity to one or several of the contents of the Kveim reagent to be central to the disease process [65-67]. One such recently identified component is vimentin, a type III intermediate filament protein expressed in mesenchymal cells and an important 
constituent of the cellular cytoskeleton [68]. Previous studies utilising mass spectrometry have, on separate occasions, identified a vimentin-derived peptide as bound to HLA-DR on alveolar macrophages in BALF of HLA-DRB ${ }^{\star} 03^{+}$sarcoidosis patients $[11,12,69]$. Intriguingly, the $H L A-D R B 1^{\star} 03$ allele has also been shown to influence the propensity and outcome of autoimmune disease systemic lupus erythematosus (SLE) [70], as well as Langerhans cell histiocytosis [71] and idiopathic inflammatory myopathies [72, 73]. In SLE, elevated levels of anti-vimentin antibodies have been found in patients with the severe kidney manifestation tubulointerstitial nephritis [74], implicating vimentin in the pathogenesis of several autoimmune disorders. Following citrullination, vimentin also acts as an antigenic target in RA [75, 76], with antibodies against citrullinated vimentin being found in the lungs prior to clinical onset of disease [77].

The disease may also stem from a combination of the aforementioned factors, as in the case of transient autoimmunity $[78,79]$. Alternatively, dual reactivity to several antigens of different origin can arise due to molecular mimicry. T-cell receptor (TCR) recognition of a microbial antigen followed by cross-reactivity of activated T-cells to a structurally similar self-peptide can result in autoimmune responses, which abate as the pathogen is cleared [80]. A third possibility is that of an autoimmune reaction following allergic hypersensitivity [81], e.g. to certain metals [82] or inorganic compounds. Recent years have seen the successful exploration of chronic beryllium disease (CBD), another granulomatous lung disorder with a strong HLA association and notable clinical similarities to sarcoidosis. It was found that all affected patients were positive for $H L A-D Q B 1^{*} 02$ and had previously been exposed to beryllium (Be), allowing $\mathrm{Be}^{2+}$ ions to interact with TCR recognition of HLA complexes presenting self-peptides in the lung. Upon $\mathrm{Be}^{2+}$ binding, T-cell epitopes would be altered, subsequently causing recognition of a self-peptide and initiation of immune responses $[81,83,84]$. The association of the $\mathrm{Be}^{2+}$ ion with the peptide-binding cleft of the HLA molecule also stabilises the TCR-HLA complex, ensuring continuous antigen presentation and constant presence of an autoreactive $\mathrm{CD}^{+} \mathrm{T}$-cell pool in the lung $[81,85,86]$. Thus, CBD patients generally experience a chronic disease, as beryllium is not readily degraded or eradicated once it has entered the lung.

Similar to CBD, where populations of clonal $\mathrm{CD} 4^{+} \mathrm{T}$-cells are observed in BALF, $\mathrm{CD} 4^{+} \mathrm{T}$-cells expressing the TCR $\alpha$-chain variable segment V $\alpha 2.3$ accumulate in the lungs of $\mathrm{HLA}-\mathrm{DRB} 1^{\star} 03^{+}$sarcoidosis patients. These expansions of TCR-specific cells are found more or less exclusively in BALF of HLA-DRB1 ${ }^{*} 03^{+}$ patients with active disease, and not in $\mathrm{HLA}-\mathrm{DRB} 1^{\star} 03^{+}$healthy individuals or patients with other pulmonary disorders [87]. They are not overrepresented in regional lymph nodes, nor in peripheral blood [88], and BALF V $\alpha 2.3^{+}$T-cell counts decrease upon clinical resolution [89]. Moreover, the higher the level of $\mathrm{V} \alpha 2.3^{+} \mathrm{T}$-cells at the time of lavage, the more rapid the resolution and better the prognosis [90]. More recently, an accumulation of $\mathrm{CD}^{+}$T-cells expressing the V $\beta 22$ TCR chain segment was identified in BALF of HLA-DRB ${ }^{\star} 03^{+}$patients [91], which prompted further investigation of HLA-DRB $1^{\star} 03$, the V $\alpha 2.3$ and V $\beta 22$ TCR segments in combination and the recognition of potential (auto)-antigenic peptides in this complex [92]. The following sections cover further arguments for the re-evaluation of sarcoidosis, and particularly LS, as an autoimmune condition and the role of vimentin as a potential target of adaptive immune responses.

\section{Disease outcome depends on $\mathrm{CD} 4^{+} \mathrm{T}$-cell balance}

As previously alluded to, disrupted balance between immune activation and regulation is a hallmark trait of autoimmune disease, and $\mathrm{CD} 4{ }^{+} \mathrm{T}$-cells are not only responsible for propagating inflammation, but also for mediating resolution, most prominently through secretion of inhibitory cytokines and expression of regulatory co-receptors. While T-cell subset patterns differ between LS and non-LS sarcoidosis, current studies clearly show that the Th-1/Th-17 paradigm alone cannot fully explain the course of disease. In one study using mass cytometry, comprehensive cluster analysis outlined the pulmonary CD4 ${ }^{+} \mathrm{T}$-cell compartment as highly dynamic, and revealed concomitant expression of several markers that may be of critical importance for disease outcome. Most prominently, CD4 ${ }^{+}$T-cell populations in LS patients were defined by higher expression of regulatory receptors CTLA-4 and PD-1, as well as inducible co-stimulator (ICOS), while non-LS cells consistently showed higher expression of effector and activation markers [35]. BRoos et al. [93] have reported on reduced expression of CTLA-4 on CD4 ${ }^{+}$T-cells in sarcoidosis patients compared to healthy individuals, and while this trend was consistent in the current study, a significant further reduction was observed in non-LS patients compared to LS. Retained CTLA-4 and PD-1 expression in LS patients, who are known to have a particularly good prognosis, expands upon the notion that the balance between immune activation and regulation is central to sarcoid inflammation. This hypothesis is further supported by the observed development of sarcoid-like granulomatous disease in patients administered IFN- $\alpha$, e.g. as a treatment for hepatitis C infection [94-96]. Conversely, the same phenomenon has been reported repeatedly in patients receiving anti-CTLA-4 or anti-PD-1 therapy (e.g. for metastatic melanoma) [93, 97-102], suggesting that abolishing this immune-dampening function in itself propagates sarcoid inflammation, seemingly regardless of antigen specificity. While some studies have argued for increased PD-1 expression to associate with reduced CD4 ${ }^{+}$T-cell proliferation and to 
contribute to the pathogenicity of sarcoidosis in the context of an infection $[103,104]$, the view of sarcoidosis as an autoimmune disorder suggests that PD-1 is probably upregulated in an effort to control adaptive immune responses to persistent tissue (self)-antigens that the patient is unable to clear. In such case, therapeutic PD-1 blockade in sarcoidosis would be counterproductive, if not directly harmful [105].

Considering the entire $\mathrm{CD} 4^{+} \mathrm{T}$-cell repertoire as a whole also provides further incentive for reassessment of the role of Tregs in sarcoidosis, which has been the subject of contradictory reports. Alternatively, either a reduction in FoxP3 ${ }^{+} \mathrm{CD}^{+}$T-cells $[106,107]$ or an increase in numbers, but with defective functional capacity, has been observed. In the latter case, reduced IL-10 production [108] and CTLA-4 expression [93], impaired survival [109] and deficient suppression of effector cell proliferation and cytokine secretion [109-112] have all been reported. In patients with CBD, antigen persistence has been observed to diminish the requirement for $\mathrm{CD} 28$ signalling in response to TCR engagement, eventually resulting in dysfunctional suppression mediated by the CTLA-4 and PD-1 pathways $[105,113]$, which could potentially parallel the situation in chronic sarcoidosis. Prior studies have reported elevated ICOS expression [107], as well as IL-10 production [108], in Tregs from LS patients, suggestive of a more self-restrictive response. In contrast, a shift towards a purely effector-driven response seems to occur in non-LS, exemplified by, e.g. a decrease in T-cell immunoglobulin mucin domain molecules that have been proposed to negatively regulate Th-1 responses [114]. More recently, a study showed that while no differences were observed between patient groups or healthy individuals in terms of FoxP3 expression, almost all FoxP3 ${ }^{+} \mathrm{CD}^{+}$T-cells in BALF, comprising both activated Th-cells and conventional Tregs, were also positive for T-bet [19], indicating a selective regulation of Th-1-driven inflammation $[115,116]$. Thus, this actively proliferating group of cells may be involved in lung-specific immune regulation and protection against harmful (auto)immune reactions, suggesting that tissue-resident $\mathrm{CD} 4^{+} \mathrm{T}$-cells may have the ability to perform certain regulatory functions without being classified as "true" Tregs; they may not even express FoxP3, and thereby be overlooked by traditional analysis methods. This, again, emphasises the difficulty of stringent subset definition and stresses the importance of distinguishing cells characterised in the circulation from cells active in their respective target organs, especially in the context of tissue-specific autoimmunity. Moreover, the critical role of CTLA- 4 and PD-1 in maintaining homeostasis and preventing immune hyperactivity call for more extensive use of these markers as surrogates for regulatory capacity of $\mathrm{CD} 4^{+} \mathrm{T}$-cells.

\section{CD4 ${ }^{+} \mathrm{T}$-cells are not the sole drivers of sarcoid inflammation}

Repeated studies have firmly established sarcoidosis as a primarily CD4 ${ }^{+}$T-cell-driven disease $[1,117]$. However, emerging evidence argue for more prominent involvement of other cellular and humoral responses than previously acknowledged $[35,118]$. By mass cytometry, a surprisingly active proliferation was observed in the $\mathrm{CD}^{+} \mathrm{T}$-cell compartment [35]. Given the observation that cytotoxic activity of $\mathrm{CD} 8^{+}$ T-cells is augmented in non-LS patients [119], it is tempting to speculate that expression of regulatory receptors and secretion of inhibitory cytokines by $\mathrm{CD}^{+}{ }^{+} \mathrm{T}$-cells also act to restrict cytotoxic $\mathrm{CD} 8^{+} \mathrm{T}$-cell activity in LS lungs, while unrestrained CTL responses, including high IFN- $\gamma$ production, in non-LS effectively lead to chronic inflammation and persistent tissue damage. Indeed, it is possible that $\mathrm{CD} 8^{+}$ T-cells constitute a more important contributor to progressive non-LS inflammation than CD4 ${ }^{+} \mathrm{T}$-cells, as suggested also by consistently lower CD4/CD8 ratios in non-LS compared to LS patients $[19,92,118,120]$.

In addition to $\mathrm{CD}^{+} \mathrm{T}$-cells, B-cells have received scant attention throughout the history of sarcoidosis research, despite being observed to undergo somatic hypermutation in the lungs and to localise around sarcoid granulomas [121], as well as to directly correlate with the percentage of T-cells in BALF [122]. However, their exceptional capacity for antigen uptake and presentation make them exceedingly interesting in the context of antigen discovery, as well as in development of novel diagnostic and prognostic tools. B-cell proliferation was recently shown to be particularly pronounced in HLA-DRB1 ${ }^{\star} 03^{+}$lungs, and to coincide with $\mathrm{CD} 4^{+} \mathrm{T}$-cell activity, indicating differences in the organisation of tertiary lymphoid structures between patient groups. Moreover, while the total immunoglobulin content in BALF was higher in HLA-DRB ${ }^{\star} 03^{-}$patients, the concentration of antibodies targeting specific autoantigenic epitopes was higher in HLA-DRB1 ${ }^{\star} 03^{+}$individuals [118], in line with a more antigen-driven, efficient and less aggressive immune response in these patients. The involvement of B-cells and particularly class-switched, antigen-specific antibodies in sarcoid inflammation may be suggestive of memory development, although more detailed studies on B-cell clonality, epitope specificity and surface markers are required to validate such statements. In addition, it was recently demonstrated that the glycosylation status of IgG antibodies differed between sarcoidosis patients and healthy controls, as well as between LS and non-LS. Non-LS patients presented with the highest ratio of agalactosylated-to-digalactosylated IgG, reflecting a more pro-inflammatory antibody repertoire, while LS patients more closely resembled the healthy control group [123]. Intriguingly, in LS patients, disease recurrence years after complete clinical remission has only been observed in HLA-DRB1 ${ }^{\star} 03^{+}$individuals [41], pointing to both a superior capacity for antigen clearance, but also possibly development of long-lived (self)-memory responses in these patients, such as have been demonstrated in experimental models of SLE [124, 125]. 


\section{Vimentin is a potential autoantigenic target of T- and B-cell inflammation in the lung}

In 2015, a molecular three-dimensional model of the TCR V $\alpha 2.3 / \mathrm{V} \beta 22-\mathrm{HLA}-\mathrm{DRB1}{ }^{*} 03$ complex was generated based on TCR sequencing data. This revealed the ideal fit of a peptide derived from the C-terminal end of cytoskeletal protein vimentin into the peptide-binding cleft, with connecting points towards all four HLA binding pockets, as well as to the CDR3 loop of the Vß22 chain, thus implicating vimentin as a potential autoantigen in sarcoidosis [92]. The same peptide has previously been isolated from HLA-DR molecules on alveolar macrophages from sarcoidosis patients [11, 69], and shown potential to stimulate IFN- $\gamma$ production by T-cells [12]. In addition, vimentin-specific antibodies were identified in BALF of sarcoidosis patients and particularly HLA-DRB1 ${ }^{\star} 03^{+}$individuals, with a switch from vimentin $\mathrm{N}$-terminal specificity in healthy individuals to C-terminal anti-vimentin antibodies (AVAs) in HLA-DRB $1^{*} 03^{+}$sarcoidosis patients [118]. Moreover, the percentage of $\mathrm{V} \alpha 2 \cdot 3^{+} \mathrm{V} \beta 22^{+} \mathrm{CD} 4^{+} \mathrm{T}$-cells in BALF correlated with specific AVA production [118], supporting the likely recognition of this peptide by $\mathrm{V} \alpha 2.3^{+} \mathrm{V} \beta 22^{+} \mathrm{CD}^{+}{ }^{+} \mathrm{T}$-cells when presented on HLA-DRB1 ${ }^{\star} 03$, as demonstrated by molecular modelling [92]. Overlapping or partially overlapping T- and B-cell epitopes have been identified, e.g. in coeliac disease [126], indicative of ongoing T-/B-cell interaction, such as could be observed as marked T- and B-cell co-localisation and proliferation in the inflamed sarcoid tissue [118]. Efficient antigen processing and presentation by $\mathrm{B}$-cells may contribute to activation and differentiation of $\mathrm{T}$-cells within and surrounding the granuloma, while T-cell help to B-cells in turn can drive somatic hypermutation and affinity maturation, ultimately resulting in the development of memory cells (figure 2).

In the context of sarcoidosis, it remains to be determined whether vimentin is a cause or effect of inflammation. Vimentin is known to be secreted from activated macrophages [127], which are abundant in the granulomatous environment, and mass spectrometry analysis verified that vimentin is readily available for uptake and processing in the lung [118]. Its release could either result from cell damage by

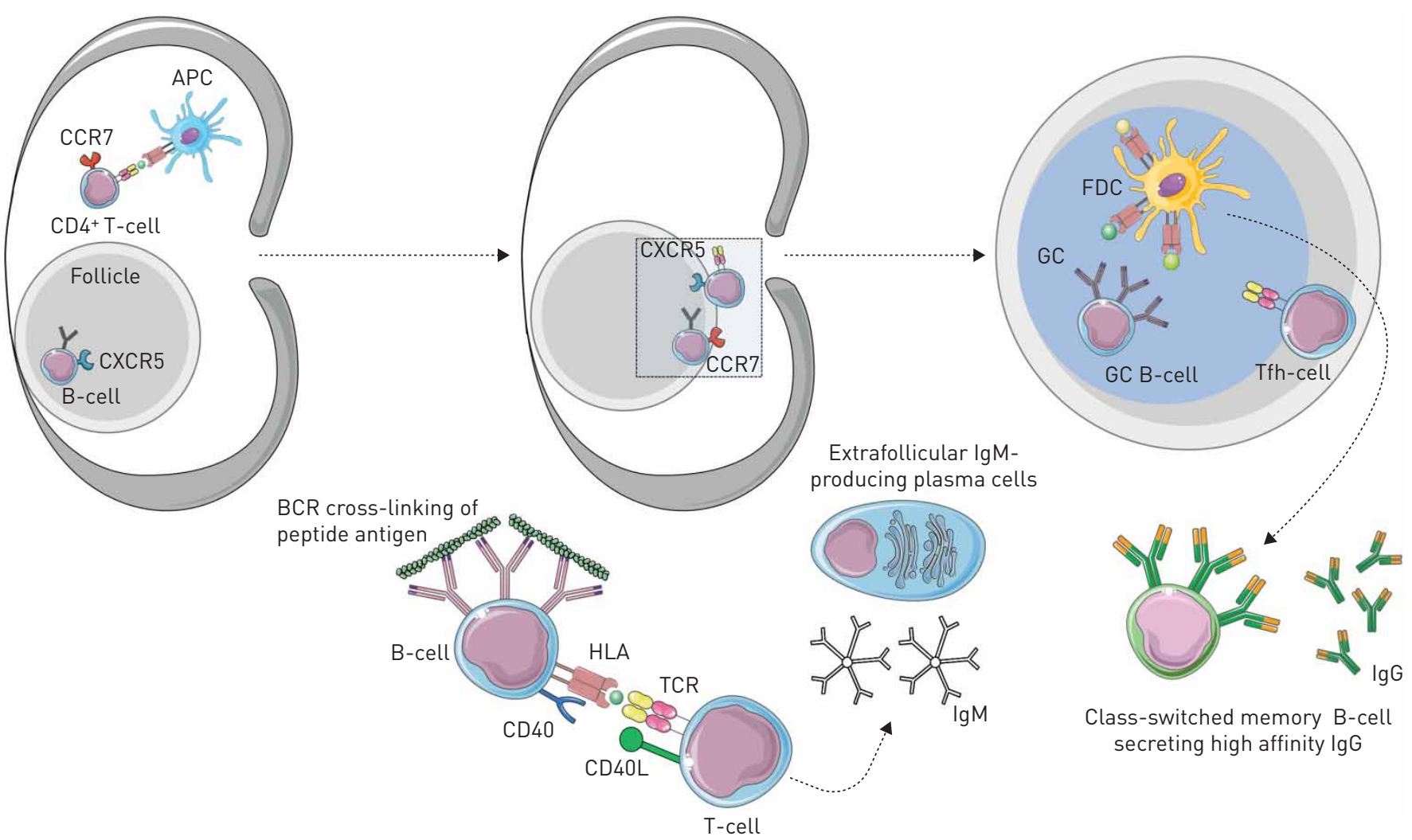

FIGURE 2 T-/B-cell interaction. Graphic representation of the initial stages of T-/B-cell interaction in secondary lymphoid organs, depicting the opposing switch in expression of chemokine receptors CXCR5 and CCR7 that allows for synchronised migration to the follicular border, subsequent interaction of $\mathrm{T}$ - and B-cells activated by the same antigen and differentiation of B-cells into antibody-producing plasma cells. Continuous antigen presentation by follicular dendritic cells (FDCs) and survival signals provided by follicular T-helper (Tfh) cells are central to the germinal centre $(\mathrm{GC})$ reaction and generation of class-switched, high-affinity B-cells. In sarcoidosis, it is suggested that such B-cells, activated by a C-terminal vimentin epitope and receiving help from T-cell receptor (TCR)-specific CD4 ${ }^{+} \mathrm{T}$-cells recognising a $\mathrm{C}$-terminal vimentin peptide, will then continue to produce antigen-specific IgG and IgA directed to the vimentin C-terminal, and possibly other structurally similar antigenic targets. APC: antigen-presenting cell; BCR: B-cell receptor; HLA: human leukocyte antigen. 
intrusion of an external factor, or as secondary reaction to a triggering event driving granuloma formation and macrophage differentiation. In favour of vimentin being a primary antigen is the identification of vimentin as a component of the Kveim reagent by EBERHARDT et al. [68], and the demonstrated capacity of this vimentin to promote IFN- $\gamma$ production by T-cells. In contrast, reports of anti-vimentin reactivity in other (auto)inflammatory conditions, such as in lupus nephritis [74], RA [75] and IPF [128], suggest that AVA reactivity is not disease-specific, but rather a sign of tissue autoimmunity, and possibly related to disease severity. This was exemplified by a weak, but detectable association between reduced lung function and higher AVA titres [118], similar to that observed in IPF [128] and with kidney pathology in SLE [74]. Alternatively, it is possible that anti-vimentin responses are a result of molecular mimicry following infection or exposure to environmental or occupational antigens. Further studies are required to elucidate the true role of vimentin in sarcoidosis pathogenesis, but these data strongly suggest its involvement to be central to both $\mathrm{T}$ - and B-cell responses.

\section{Functionally heterogeneous $\mathrm{V} \alpha 2.3^{+} \mathrm{V} \beta 22^{+} \mathrm{CD} 4^{+} \mathrm{T}$-cells are key mediators of disease outcome}

The expansion of $\mathrm{V} \alpha 2.3^{+} \mathrm{V} \beta 22^{+} \mathrm{CD} 4^{+} \mathrm{T}$-cells specifically in HLA-DRB1*03 ${ }^{+}$patients $[92,129]$ implicates these cells as central to the process of antigen recognition. Previous studies on $\mathrm{V} \alpha 2.3^{+} \mathrm{T}$-cells, prior to the discovery of joint expression with $\mathrm{V} \beta 22$, have clearly demonstrated that this expansion, which ranges up to 10-fold during active disease, unfailingly normalises after clinical recovery [89], which is consistent with an antigen-specific response that ebbs out following antigen clearance. With high expression of CD69, T-bet, ROR $\gamma$ T, CXCR3, CCR6, but not FoxP3 and only low levels of CD27, this population also demonstrates an advanced state of differentiation $[19,92]$. Interestingly, a less dramatic, but significant, expansion of V $\alpha 2.3^{+}$ $\mathrm{CD} 4^{+} \mathrm{T}$-cells was observed in patients negative for HLA-DRB1 ${ }^{\star} 03$, but positive for HLA-DRB3 ${ }^{\star} 01$. These two HLA molecules are similar in structure and function, and able to present a highly similar peptide antigen repertoire [130]. Accordingly, molecular modelling visualised the connection between TCR and HLA-DRB $1^{\star} 03$ as primarily mediated by the V $\alpha 2.3$ segment, while V $\beta 22$ mainly interacted with the HLA-bound peptide, but also with V $\alpha 2.3$ [92].

However, as carriage of $H L A-D R B 1^{\star} 03$ is most frequent in LS patients, who have a favourable prognosis, and LS is now proposed to be an autoimmune condition, the intriguing, and seemingly contradictory, question remains as to how autoreactive cells can contribute to disease resolution. One hypothesis is that with an intracellular antigen such as vimentin, antigen-specific cells might aid in its clearance from the extracellular environment, where its components may drive unwanted inflammatory reactions. Differentiated $\mathrm{CD}^{+}$T-cells with the capacity to produce a broad range of cytokines and orchestrate a coordinated immune response could thereby cause an initially more intense reaction, represented by the acute symptomatic onset observed in LS, but also force resolution of granulomas and thereby disease. Along these lines, the T-/B-cell interaction implicated especially in HLA-DRB1 ${ }^{\star} 03^{+}$patients would further suggest that AVAs may act to opsonise or neutralise extracellular vimentin, possibly participating in its removal. Consequently, in the absence of HLA-DRB1*03 and $\mathrm{V} \alpha 2.3^{+} \mathrm{V} \beta 22^{+} \mathrm{T}$-cells, as in most non-LS patients, neither clearance nor immune regulation would be as efficient, resulting in prolonged IFN- $\gamma$ production, less-specific humoral responses, unrestricted cytotoxic $\mathrm{CD} 8^{+} \mathrm{T}$-cell activity and eventually, due to lack of regulatory mechanisms, irreversible tissue damage that may progress to pulmonary fibrosis (figure 3). As vimentin is a vital component of mesenchymal cells, it is also intriguing to speculate on the role of fibroblasts and their contribution to the granulomatous environment and in resolving versus chronic disease. Excessive fibroblast activation and remodelling within the granuloma may contribute to driving a secondary autoimmune reaction, where less efficient clearance of free vimentin from the extracellular environment and other factors such as CD44 upregulation propagates a chronic pro-inflammatory response, particularly in HLA-DRB1 $03^{-}$patients. Notably, a recent publication suggested involvement of PD-1 signalling in fibrotic development [131], inferring that the disrupted regulatory pathways observed in sarcoidosis may over time have far-reaching consequences if inflammation is allowed to persist.

\section{Concluding remarks and future perspectives}

A series of consecutive studies spanning several years delineate a critical role for TCR-specific $\mathrm{V} \alpha 2.3^{+} \mathrm{V} \beta 22^{+} \mathrm{CD}^{+}{ }^{+} \mathrm{T}$-cells in antigen recognition and possibly clearance, resulting in an active, but transient, inflammatory response. The high differentiation state of these cells, exemplified by expression of multiple transcription factors, chemokine receptors, activation and regulatory markers, coupled with the remarkable degree of T-cell clonality observed within and between patients positive for the HLA-DRB1 ${ }^{\star} 03$ allele, are all strongly indicative of specific antigen exposure. Moreover, correlation of percentage of $\mathrm{V} \alpha 2.3^{+} \mathrm{V} \beta 22^{+} \mathrm{T}$-cells with titres of specific antibodies suggest interaction between $\mathrm{CD}^{+}{ }^{+} \mathrm{T}$-cells and B-cells in the inflamed lung, with potential implications for improved prognostic assessment. While this review 
Presentation of antigenic peptides on HLA-DRB $1 * 03$

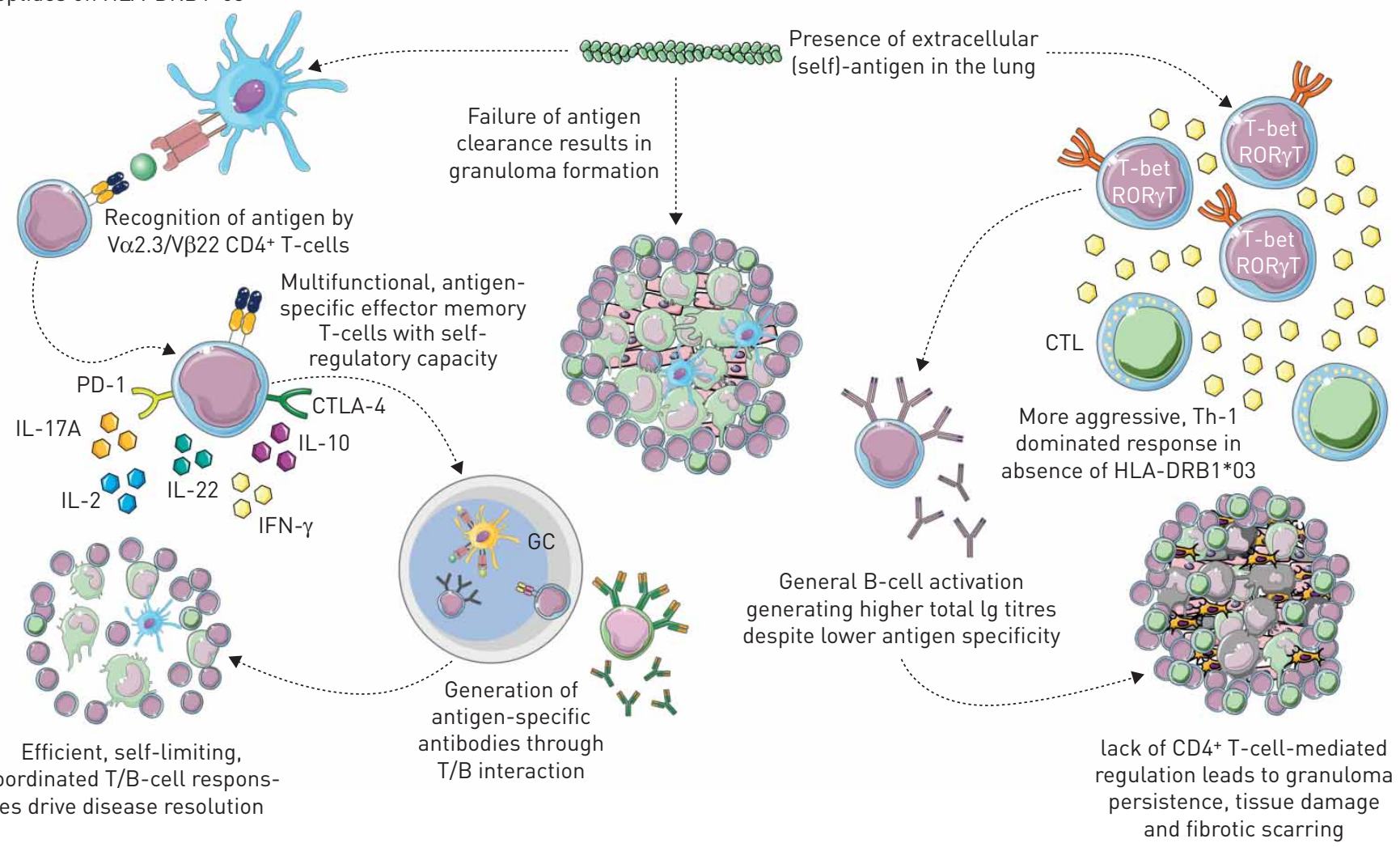

FIGURE 3 Proposed mechanism of disease in T-bet/RORyT-balanced (LS) and T-bet-dominated (non-LS) sarcoidosis. Graphic summary of the proposed immunological mechanisms underlying LS and non-LS. The presence of a still unknown (self)-antigen in the pulmonary compartment triggers recognition and uptake by alveolar macrophages and dendritic cells. In both disease forms, inability to completely clear the antigenic source results in its encapsulation and formation of characteristic granulomas. In LS, and particularly human leukocyte antigen (HLA)-DRB1*03 ${ }^{+}$ patients, T-cell receptor (TCR)-specific $\mathrm{CD}^{+} \mathrm{T}$-cells are able to recognise peptide antigens and respond with a broad range of cytokine mediators. At the same time, these differentiated effector cells, expressing both T-bet and ROR $\gamma \mathrm{T}$, appear able to restrict immune activity, as noted by maintained $\mathrm{CD}^{+}$T-cell expression of regulatory receptors CTLA-4 and PD-1. CD4 ${ }^{+}$T-cells in HLA-DRB $1^{*} 03^{+}$patients are further believed to interact with B-cells, giving rise to antigen-specific antibodies. Ultimately, an efficient antigen-driven T-/B-cell response contributes to spontaneous dissolution of granulomas and resolution of disease. In contrast, non-LS CD4 ${ }^{+}$T-cells demonstrate a more aggressive, T-helper (Th)-1-dominant phenotype primarily expressing T-bet and producing high levels of interferon (IFN)- $\gamma$. Moreover, higher expression of adhesion marker CD44 may contribute to granuloma persistence, while lack of regulatory capacity in $\mathrm{CD} 4^{+} \mathrm{T}$-cells allows for unrestrained cytotoxic T-cell (CTL) proliferation, resulting in tissue damage. B-cell activation occurs in absence of germinal centre (GC) formation, resulting in higher total Ig concentration, but a lower degree of antigen specificity. Together, these processes of potent but less antigen-targeted lymphocytic activity produce a state of chronic inflammation and tissue disruption, with a risk of developing permanent fibrotic scarring.

has focused particularly on vimentin as a candidate target of both T-cells and B-cells in the lung, the involvement of vimentin in several other autoimmune diseases questions whether this is an occurrence specific for sarcoidosis, or common for tissue manifestations of several chronic inflammatory conditions. While the triggering incident, together with genetic background, are decisive for the emergence of a certain disease phenotype, the studies highlighted here also indicate that the order of events implicated in sarcoid pathogenesis, such as antigen recognition by T-cells, vimentin release, loss of regulatory balance and development of humoral responses, among others, may differ between patients, who will thus have different immunological prerequisites for management of the insult. Importantly, as indicated by the studies covered in this review, the traditional depiction of sarcoidosis as a solely $\mathrm{CD} 4^{+} \mathrm{T}$-cell- and mainly Th-1-driven disease is now under dispute, and not only should regulatory features of T-cells be further explored, but also the role of B-cells, $\mathrm{CD}^{+} \mathrm{T}$-cells, $\mathrm{DCs}$ and other tissue-resident immune cells with potential impact on antigen processing, presentation and downstream effector functions.

Future studies should also aim for more stringent and consistent subclassification of patients, not merely by LS and non-LS, which are readily distinguished based on characteristic symptoms but still frequently grouped together, but also by HLA type, sex, presence of extrapulmonary symptoms and organ involvement. This would be of most benefit to the larger group of non-LS patients, where prognosis is poorer and even less is known with regards to antigenic triggers. The disparity in symptomatic 
presentation between different ethnic groups, HLA backgrounds or sexes indicate sarcoidosis to be not a single disease entity, but rather a spectrum of disorders, and proper classification of these conditions is essential for correct clinical management as well as further research. In this review, several examples show LS and non-LS to harbour similar, but significantly different immunological traits, which are likely to be instrumental in disease progression and outcome. The seemingly less aggressive, more antigen-driven, and more self-limiting immune response in LS relates well to the active inflammation and often spontaneous resolution observed in this patient group. Ultimately, the long-term goal of both antigen discovery and detailed immunological studies should be to improve diagnostic and especially prognostic procedures, create more precise and individualised therapeutic options, and if possible, to develop preventive measures. For this reason, understanding not only the cause of disease, which may well differ between LS and non-LS, but also the immunological response to this initial pathogenic event is critical. Data gathered from human samples offer a mere snapshot of a complex disease course, and as exemplified by an increasing number of studies, the cellular composition in the lung markedly differs from that of peripheral blood, wherewith sampling from the periphery is insufficient for proper assessment of the present immunological state of the patient. Despite the invasive nature of bronchoscopy, repeated investigations during follow-up and after clinical remission would be highly desirable from a research perspective, and provide information that could prove essential in unravelling the mechanisms that govern disease resolution and progression. Furthermore, systematic exploration into the affected tissue should be prioritised in order to gain insight into differences in granuloma formation and persistence between clinical phenotypes, which may prove useful in the development of new treatments. Despite being highly anticipated from a clinical perspective, proper understanding of vital immune reactions in the target organ is likely to be required prior to successful identification of any diagnostic and/or prognostic marker readily available through blood sampling.

As Oscar Wilde once wrote, "The truth is rarely pure and never simple", and it is indeed unlikely to be the case in the unresolved mystery that is sarcoid pathogenesis; perhaps we have only begun to scratch at the surface of a far larger group of related, but not identical, diseases. Hopefully, however, ongoing research is helping us to find the missing pieces of the sarcoidosis puzzle.

Conflict of interest: None declared.

Support statement: Financial support in the form of research grants was received from The Swedish Heart Lung Foundation, The Swedish Research Council, The King Oscar II Jubilee Foundation, King Gustaf V's and Queen Victoria's Freemasons' Foundation, and Karolinska Institutet. Support was also provided through the regional agreement on medical training and clinical research (ALF) between Stockholm County Council and Karolinska Institutet. Funding information for this article has been deposited with the Crossref Funder Registry.

\section{References}

Iannuzzi MC, Rybicki BA, Teirstein AS. Sarcoidosis. N Engl J Med 2007; 357: 2153-2165.

Valeyre D, Prasse A, Nunes H, et al. Sarcoidosis. Lancet 2014; 383: 1155-1167.

Saidha S, Sotirchos ES, Eckstein C. Etiology of sarcoidosis: does infection play a role? Yale J Biol Med 2012; 85: $133-141$.

4 Chen ES, Wahlström J, Song Z, et al. T cell responses to mycobacterial catalase-peroxidase profile a pathogenic antigen in systemic sarcoidosis. J Immunol 2008; 181: 8784-8796.

5 Song Z, Marzilli L, Greenlee BM, et al. Mycobacterial catalase-peroxidase is a tissue antigen and target of the adaptive immune response in systemic sarcoidosis. J Exp Med 2005; 201: 755-767.

6 Eishi Y, Suga M, Ishige I, et al. Quantitative analysis of mycobacterial and propionibacterial DNA in lymph nodes of Japanese and European patients with sarcoidosis. J Clin Microbiol 2002; 40: 198-204.

7 Ishige I, Eishi Y, Takemura T, et al. Propionibacterium acnes is the most common bacterium commensal in peripheral lung tissue and mediastinal lymph nodes from subjects without sarcoidosis. Sarcoidosis Vasc Diffuse Lung Dis 2005; 22: 33-42.

8 Negi M, Takemura T, Guzman J, et al. Localization of Propionibacterium acnes in granulomas supports a possible etiologic link between sarcoidosis and the bacterium. Mod Pathol 2012; 25: 1284-1297.

9 Newman KL, Newman LS. Occupational causes of sarcoidosis. Curr Opin Allergy Clin Immunol 2012; 12 : $145-150$.

10 Chen ES, Song Z, Willett MH, et al. Serum amyloid A regulates granulomatous inflammation in sarcoidosis through Toll-like receptor-2. Am J Respir Crit Care Med 2010; 181: 360-373.

11 Wahlström J, Dengjel J, Persson B, et al. Identification of HLA-DR-bound peptides presented by human bronchoalveolar lavage cells in sarcoidosis. J Clin Invest 2007; 117: 3576-3582.

12 Wahlström J, Dengjel J, Winqvist O, et al. Autoimmune T cell responses to antigenic peptides presented by bronchoalveolar lavage cell HLA-DR molecules in sarcoidosis. Clin Immunol 2009; 133: 353-363.

13 Chen ES, Moller DR. Sarcoidosis - scientific progress and clinical challenges. Nat Rev Rheumatol 2011; 7: 457-467.

14 Moller DR, Forman JD, Liu MC, et al. Enhanced expression of IL-12 associated with Th1 cytokine profiles in active pulmonary sarcoidosis. J Immunol 1996; 156: 4952-4960.

15 Shigehara K, Shijubo N, Ohmichi M, et al. IL-12 and IL-18 are increased and stimulate IFN- $\gamma$ production in sarcoid lungs. J Immunol 2001; 166: 642-649. 
Wahlström J, Katchar K, Wigzell H, et al. Analysis of intracellular cytokines in $\mathrm{CD}^{+}$and $\mathrm{CD}^{+}$lung and blood T cells in sarcoidosis. Am J Respir Crit Care Med 2001; 163: 115-121.

Antoniou KM, Tzouvelekis A, Alexandrakis MG, et al. Upregulation of Th1 cytokine profile (IL-12, IL-18) in bronchoalveolar lavage fluid in patients with pulmonary sarcoidosis. J Interferon Cytokine Res 2006; 26: 400-405.

Katchar K, Eklund A, Grunewald J. Expression of Th1 markers by lung accumulated T cells in pulmonary sarcoidosis. J Intern Med 2003; 254: 564-571.

Kaiser Y, Lepzien R, Kullberg S, et al. Expanded lung T-bet ${ }^{+} \mathrm{ROR} \gamma \mathrm{T}^{+} \mathrm{CD} 4^{+} \mathrm{T}$-cells in sarcoidosis patients with a favourable disease phenotype. Eur Respir J 2016; 48: 484-494.

Ramstein J, Broos CE, Simpson LJ, et al. Interferon- $\gamma$-producing T-helper 17.1 cells are increased in sarcoidosis and are more prevalent than T-helper type 1 cells. Am J Respir Crit Care Med 2016; 193: 1281-1291.

Broos CE, Koth LL, van Nimwegen M, et al. Increased T-helper 17.1 cells in sarcoidosis mediastinal lymph nodes. Eur Respir J 2018; 51: 1701124.

Tøndell A, Moen T, Børset M, et al. Bronchoalveolar lavage fluid IFN- $\gamma^{+}$Th17 cells and regulatory T cells in pulmonary sarcoidosis. Mediators Inflamm 2014; 2014: 438070.

Ostadkarampour M, Eklund A, Moller D, et al. Higher levels of interleukin IL-17 and antigen-specific IL-17 responses in pulmonary sarcoidosis patients with Löfgren's syndrome. Clin Exp Immunol 2014; 178: 342-352.

Lexberg MH, Taubner A, Albrecht I, et al. IFN- $\gamma$ and IL-12 synergize to convert in vivo generated Th17 into Th1/Th17 cells. Eur J Immunol 2010; 40: 3017-3027.

Hueber W, Sands BE, Lewitzky S, et al. Secukinumab, a human anti-IL-17A monoclonal antibody, for moderate to severe Crohn's disease: unexpected results of a randomised, double-blind placebo-controlled trial. Gut 2012; 61: $1693-1700$

Scriba TJ, Kalsdorf B, Abrahams DA, et al. Distinct, specific IL-17- and IL-22-producing CD4 ${ }^{+} \mathrm{T}$ cell subsets contribute to the human anti-mycobacterial immune response. J Immunol 2008; 180: 1962-1970.

Whittington HA, Armstrong L, Uppington KM, et al. Interleukin-22: a potential immunomodulatory molecule in the lung. Am J Respir Cell Mol Biol 2004; 31: 220-226.

McGeachy MJ, Bak-Jensen KS, Chen Y, et al. TGF- $\beta$ and IL- 6 drive the production of IL-17 and IL-10 by T cells and restrain $\mathrm{T}_{\mathrm{H}^{-}}-17$ cell-mediated pathology. Nat Immunol 2007; 8: 1390-1397.

Symons A, Budelsky AL, Towne JE. Are Th17 cells in the gut pathogenic or protective? Mucosal Immunol 2012; 5: 4-6.

Durham LE, Kirkham BW, Taams LS. Contribution of the IL-17 pathway to psoriasis and psoriatic arthritis Curr Rheumatol Rep 2015; 17: 55.

Luchtman DW, Ellwardt E, Larochelle C, et al. IL-17 and related cytokines involved in the pathology and immunotherapy of multiple sclerosis: current and future developments. Cytokine Growth Factor Rev 2014; 25: 403-413.

Malakouti M, Brown GE, Wang E, et al. The role of IL-17 in psoriasis. J Dermatolog Treat 2015; 26: 41-44. pathogenesis and developments in cytokine immunotherapy. Cytokine 2015; 74: 101-107.

Zhang Y, Li Y, Lv TT, et al. Elevated circulating Th17 and follicular helper $\mathrm{CD}^{+}{ }^{+} \mathrm{T}$ cells in patients with rheumatoid arthritis. APMIS 2015; 123: 659-666.

Kaiser Y, Lakshmikanth T, Chen Y, et al. Mass cytometry identifies distinct lung $\mathrm{CD}^{+}{ }^{+} \mathrm{T}$ cell patterns in Löfgren's syndrome and non-Löfgren's syndrome sarcoidosis. Front Immunol 2017; 8: 1130.

Ikehata A, Tomichi N. CD44v6 expression in granuloma of Crohn's disease. Am J Gastroenterol 2000; 95: 3325-3326.

Ohyashiki K, Ando K, Hayashi S, et al. Soluble CD44 level in non-malignant disorders is associated with autoimmune backgrounds. Autoimmunity 1999; 30: 35-36.

Kasuga I, Minemura K, Nasu H, et al. Elevated serum soluble CD44 level in sarcoidosis. Int J Mol Med 2000; 6: 679-682.

Linke M, Pham HT, Katholnig K, et al. Chronic signaling via the metabolic checkpoint kinase mTORC1 induces macrophage granuloma formation and marks sarcoidosis progression. Nat Immunol 2017; 18: 293-302.

Gadhoum SZ, Madhoun NY, Abuelela AF, et al. Anti-CD44 antibodies inhibit both mTORC1 and mTORC2: a new rationale supporting CD44-induced AML differentiation therapy. Leukemia 2016; 30: 2397-2401.

Grunewald J, Eklund A. Löfgren's syndrome: human leukocyte antigen strongly influences the disease course. Am J Respir Crit Care Med 2009; 179: 307-312.

Rivera NV, Ronninger M, Shchetynsky K, et al. High-density genetic mapping identifies new susceptibility variants in sarcoidosis phenotypes and shows genomic-driven phenotypic differences. Am J Respir Crit Care Med 2016; 193: 1008-1022.

Moller DR. Potential etiologic agents in sarcoidosis. Proc Am Thorac Soc 2007; 4: 465-468.

Chen ES, Moller DR. Etiologies of sarcoidosis. Clin Rev Allergy Immunol 2015; 49: 6-18.

Dubaniewicz A, Kalinowski L, Dudziak M, et al. Peroxynitrite in sarcoidosis: relation to Mycobacterium stationary phase. Adv Exp Med Biol 2015; 866: 41-49.

Drake WP, Richmond BW, Oswald-Richter K, et al. Effects of broad-spectrum antimycobacterial therapy on chronic pulmonary sarcoidosis. Sarcoidosis Vasc Diffuse Lung Dis 2013; 30: 201-211.

Drake WP, Oswald-Richter K, Richmond BW, et al. Oral antimycobacterial therapy in chronic cutaneous sarcoidosis: a randomized, single-masked, placebo-controlled study. JAMA Dermatol 2013; 149: 1040-1049.

Nagata K, Eishi Y, Uchida K, et al. Immunohistochemical detection of Propionibacterium acnes in the retinal granulomas in patients with ocular sarcoidosis. Sci Rep 2017; 7: 15226.

Asakawa N, Uchida K, Sakakibara M, et al. Immunohistochemical identification of Propionibacterium acnes in granuloma and inflammatory cells of myocardial tissues obtained from cardiac sarcoidosis patients. PLoS One 2017; 12: e0179980.

Goto H, Usui $\mathrm{Y}$, Umazume A, et al. Propionibacterium acnes as a possible pathogen of granuloma in patients with ocular sarcoidosis. Br J Ophthalmol 2017; 101: 1510-1513.

Yang G, Eishi Y, Raza A, et al. Propionibacterium acnes-associated neurosarcoidosis: a case report with review of the literature. Neuropathology 2018; 38: 159-164. 
Zimmermann A, Knecht H, Häsler R, et al. Atopobium and Fusobacterium as novel candidates for sarcoidosis-associated microbiota. Eur Respir J 2017; 50: 1600746.

Saboor SA, Johnson NM, McFadden J. Detection of mycobacterial DNA in sarcoidosis and tuberculosis with polymerase chain reaction. Lancet 1992; 339: 1012-1015.

Patterson KC, Chen ES. The pathogenesis of pulmonary sarcoidosis and implications for treatment. Chest 2018; 153: $1432-1442$.

Demirkok SS, Basaranoglu M, Coker E, et al. Seasonality of the onset of symptoms, tuberculin test anergy and Kveim positive reaction in a large cohort of patients with sarcoidosis. Respirology 2007; 12: 591-593.

Doria A, Zen M, Bettio S, et al. Autoinflammation and autoimmunity: bridging the divide. Autoimmun Rev 2012; 12: 22-30.

Rybicki BA, Iannuzzi MC, Frederick MM, et al. Familial aggregation of sarcoidosis. A case-control etiologic study of sarcoidosis (ACCESS). Am J Respir Crit Care Med 2001; 164: 2085-2091.

Sverrild A, Backer V, Kyvik KO, et al. Heredity in sarcoidosis: a registry-based twin study. Thorax 2008; 63: 894-896.

Grunewald J. HLA associations and Löfgren's syndrome. Expert Rev Clin Immunol 2012; 8: 55-62.

Johard U, Eklund A. Recurrent Löfgren's syndrome in three patients with sarcoidosis. Sarcoidosis 1993; 10: 125-127.

Mañá J, Montero A, Vidal M, et al. Recurrent sarcoidosis: a study of 17 patients with 24 episodes of recurrence. Sarcoidosis Vasc Diffuse Lung Dis 2003; 20: 212-221.

Kveim A. En ny og spesifikk kutan - reaksjon ved Boecks sarcoid [A new and specific cutaneous reaction in Boeck's sarcoid]. Nord Med 1941; 9: 169-172.

Kveim A. Some remarks on the aetiology of Boeck's sarcoid. Acta Derm Venereol 1948; 28: 169.

Chase MW. The preparation and standardization of Kveim testing antigen. Am Rev Respir Dis 1961; 84: 86-88.

Richter E, Kataria YP, Zissel G, et al. Analysis of the Kveim-Siltzbach test reagent for bacterial DNA. Am J Respir Crit Care Med 1999; 159: 1981-1984.

Teirstein AS. Kveim antigen: what does it tell us about causation of sarcoidosis? Semin Respir Infect 1998; 13: 206-211.

Lindahl M, Andersson O, Ripe E, et al. Stimulation of bronchoalveolar lavage (BAL) and blood lymphocytes by Kveim antigen, tuberculin and concanavalin A in sarcoidosis. Br J Dis Chest 1988; 82: 386-393.

Eberhardt C, Thillai M, Parker R, et al. Proteomic analysis of Kveim reagent identifies targets of cellular immunity in sarcoidosis. PLoS One 2017; 12: e0170285.

Heyder T, Kohler M, Tarasova NK, et al. Approach for identifying human leukocyte antigen (HLA)-DR bound peptides from scarce clinical samples. Mol Cell Proteomics 2016; 15: 3017-3029.

Morris DL, Fernando MM, Taylor KE, et al. MHC associations with clinical and autoantibody manifestations in European SLE. Genes Immun 2014; 15: 210-217.

Bernstrand C, Carstensen H, Jakobsen B, et al. Immunogenetic heterogeneity in single-system and multisystem Langerhans cell histiocytosis. Pediatr Res 2003; 54: 30-36.

Mastaglia FL, Needham M, Scott A, et al. Sporadic inclusion body myositis: HLA-DRB1 allele interactions influence disease risk and clinical phenotype. Neuromuscul Disord 2009; 19: 763-765.

Rothwell S, Cooper RG, Lundberg IE, et al. Dense genotyping of immune-related loci in idiopathic inflammatory myopathies confirms HLA alleles as the strongest genetic risk factor and suggests different genetic background for major clinical subgroups. Ann Rheum Dis 2016; 75: 1558-1566.

Kinloch AJ, Chang A, Ko K, et al. Vimentin is a dominant target of in situ humoral immunity in human lupus tubulointerstitial nephritis. Arthritis Rheumatol 2014; 66: 3359-3370.

Wegner N, Lundberg K, Kinloch A, et al. Autoimmunity to specific citrullinated proteins gives the first clues to the etiology of rheumatoid arthritis. Immunol Rev 2010; 233: 34-54.

Vossenaar ER, Després N, Lapointe E, et al. Rheumatoid arthritis specific anti-Sa antibodies target citrullinated vimentin. Arthritis Res Ther 2004; 6: R142-R150.

Kinloch AJ, Lundberg KE, Moyes D, et al. Pathogenic role of antibodies to citrullinated proteins in rheumatoid arthritis. Expert Rev Clin Immunol 2006; 2: 365-375.

Cervera R, Asherson RA. Antiphospholipid syndrome associated with infections: clinical and microbiological characteristics. Immunobiology 2005; 210: 735-741.

Gudjonsson JE, Johnston A, Sigmundsdottir H, et al. Immunopathogenic mechanisms in psoriasis. Clin Exp Immunol 2004; 135: 1-8.

Cusick MF, Libbey JE, Fujinami RS. Molecular mimicry as a mechanism of autoimmune disease. Clin Rev Allergy Immunol 2012; 42: 102-111.

Clayton GM, Wang Y, Crawford F, et al. Structural basis of chronic beryllium disease: linking allergic hypersensitivity and autoimmunity. Cell 2014; 158: 132-142.

Newman LS. Metals that cause sarcoidosis. Semin Respir Infect 1998; 13: 212-220.

Falta MT, Pinilla C, Mack DG, et al. Identification of beryllium-dependent peptides recognized by CD $4^{+} \mathrm{T}$ cells in chronic beryllium disease. J Exp Med 2013; 210: 1403-1418.

Bowerman NA, Falta MT, Mack DG, et al. Identification of multiple public TCR repertoires in chronic beryllium disease. J Immunol 2014; 192: 4571-4580.

Dai S, Falta MT, Bowerman NA, et al. T cell recognition of beryllium. Curr Opin Immunol 2013; 25: 775-780. Petukh M, Wu B, Stefl S, et al. Chronic beryllium disease: revealing the role of beryllium ion and small peptides binding to HLA-DP2. PLoS One 2014; 9: e111604.

Grunewald J, Janson $\mathrm{CH}$, Eklund $\mathrm{A}$, et al. Restricted $\mathrm{V}_{\alpha} 2.3$ gene usage by $\mathrm{CD}^{+} \mathrm{T}$ lymphocytes in bronchoalveolar lavage fluid from sarcoidosis patients correlates with HLA-DR3. Eur J Immunol 1992; 22: 129-135.

Darlington P, Haugom-Olsen H, von Sivers K, et al. T-cell phenotypes in bronchoalveolar lavage fluid, blood and lymph nodes in pulmonary sarcoidosis - indication for an airborne antigen as the triggering factor in sarcoidosis. J Intern Med 2012; 272: 465-471.

Planck A, Eklund A, Grunewald J. Markers of activity in clinically recovered human leukocyte antigen-DR17-positive sarcoidosis patients. Eur Respir J 2003; 21: 52-57. 
Grunewald J, Berlin M, Olerup O, et al. Lung T-helper cells expressing T-cell receptor AV2S3 associate with clinical features of pulmonary sarcoidosis. Am J Respir Crit Care Med 2000; 161: 814-818.

91 Ahlgren KM, Ruckdeschel T, Eklund A, et al. T cell receptor-V $\beta$ repertoires in lung and blood $\mathrm{CD}^{+}$and $\mathrm{CD} 8^{+}$ T cells of pulmonary sarcoidosis patients. BMC Pulm Med 2014; 14: 50.

92 Grunewald J, Kaiser Y, Ostadkarampour M, et al. T-cell receptor-HLA-DRB1 associations suggest specific antigens in pulmonary sarcoidosis. Eur Respir J 2016; 47: 898-909.

93 Broos CE, van Nimwegen M, In 't Veen JC, et al. Decreased cytotoxic T-lymphocyte antigen 4 expression on regulatory T cells and Th17 cells in sarcoidosis: double trouble? Am J Respir Crit Care Med 2015; 192: $763-765$.

94 Viana de Andrade AC, Brito EA, Harris OM, et al. Development of systemic sarcoidosis and xanthoma planum during multiple sclerosis treatment with interferon-beta 1a: case report. Int J Dermatol 2015; 54: e140-e145.

95 Chiang CH, Lai FJ. Sarcoidosis on the injection sites following treatment of interferon-alpha and ribavirin for hepatitis C. J Formos Med Assoc 2014; 113: 981-982.

96 Jeon EK, Hong J, Hong SH, et al. First reported case of interferon-alpha-induced sarcoidosis in an Asian patient with malignant melanoma. Asia Pac J Clin Oncol 2014; 12: e347-e349.

97 Walker LS, Sansom DM. The emerging role of CTLA4 as a cell-extrinsic regulator of T cell responses. Nat Rev Immunol 2011; 11: 852-863.

98 Birnbaum MR, Ma MW, Fleisig S, et al. Nivolumab-related cutaneous sarcoidosis in a patient with lung adenocarcinoma. JAAD Case Rep 2017; 3: 208-211.

99 Danlos FX, Pagès C, Baroudjian B, et al. Nivolumab-induced sarcoid-like granulomatous reaction in a patient with advanced melanoma. Chest 2016; 149: e133-e136.

100 Montaudié $\mathrm{H}$, Pradelli J, Passeron T, et al. Pulmonary sarcoid-like granulomatosis induced by nivolumab. Br J Dermatol 2017; 176: 1060-1063.

101 Suozzi KC, Stahl M, Ko CJ, et al. Immune-related sarcoidosis observed in combination ipilimumab and nivolumab therapy. JAAD Case Rep 2016; 2: 264-268.

102 Vogel WV, Guislain A, Kvistborg P, et al. Ipilimumab-induced sarcoidosis in a patient with metastatic melanoma undergoing complete remission. J Clin Oncol 2012; 30: e7-e10.

103 Braun NA, Celada LJ, Herazo-Maya JD, et al. Blockade of the programmed death-1 pathway restores sarcoidosis $\mathrm{CD}^{+}{ }^{+}$T-cell proliferative capacity. Am J Respir Crit Care Med 2014; 190: 560-571.

104 Celada LJ, Rotsinger JE, Young A, et al. Programmed death-1 inhibition of phosphatidylinositol 3-kinase/AKT/ mechanistic target of rapamycin signaling impairs sarcoidosis $\mathrm{CD}^{+} \mathrm{T}$ cell proliferation. Am $\mathrm{J}$ Respir Cell Mol Biol 2017; 56: 74-82.

105 Palmer BE, Mack DG, Martin AK, et al. Up-regulation of programmed death-1 expression on beryllium-specific $\mathrm{CD}^{+}{ }^{+} \mathrm{T}$ cells in chronic beryllium disease. J Immunol 2008; 180: 2704-2712.

106 Idali F, Wahlström J, Müller-Suur C, et al. Analysis of regulatory T cell associated forkhead box P3 expression in the lungs of patients with sarcoidosis. Clin Exp Immunol 2008; 152: 127-137.

107 Sakthivel P, Grunewald J, Eklund A, et al. Pulmonary sarcoidosis is associated with high-level inducible co-stimulator (ICOS) expression on lung regulatory T cells - possible implications for the ICOS/ICOS-ligand axis in disease course and resolution. Clin Exp Immunol 2016; 183: 294-306.

108 Idali F, Wiken M, Wahlström J, et al. Reduced Th1 response in the lungs of HLA-DRB1 ${ }^{\star} 0301$ patients with pulmonary sarcoidosis. Eur Respir J 2006; 27: 451-459.

109 Broos CE, van Nimwegen M, Kleinjan A, et al. Impaired survival of regulatory T cells in pulmonary sarcoidosis. Respir Res 2015; 16: 108.

110 Miyara M, Amoura Z, Parizot C, et al. The immune paradox of sarcoidosis and regulatory T cells. $J$ Exp Med 2006; 203: 359-370.

111 Taflin C, Miyara M, Nochy D, et al. FoxP3 ${ }^{+}$regulatory T cells suppress early stages of granuloma formation but have little impact on sarcoidosis lesions. Am J Pathol 2009; 174: 497-508.

112 Rappl G, Pabst S, Riemann D, et al. Regulatory T cells with reduced repressor capacities are extensively amplified in pulmonary sarcoid lesions and sustain granuloma formation. Clin Immunol 2011; 140: 71-83.

113 Chain JL, Martin AK, Mack DG, et al. Impaired function of CTLA-4 in the lungs of patients with chronic beryllium disease contributes to persistent inflammation. J Immunol 2013; 191: 1648-1656.

114 Idali F, Wahlström J, Dahlberg B, et al. Altered expression of T cell immunoglobulin-mucin (TIM) molecules in bronchoalveolar lavage CD4 ${ }^{+} \mathrm{T}$ cells in sarcoidosis. Respir Res 2009; 10: 42.

115 Koch MA, Tucker-Heard G, Perdue NR, et al. The transcription factor T-bet controls regulatory T cell homeostasis and function during type 1 inflammation. Nat Immunol 2009; 10: 595-602.

116 Wei G, Wei L, Zhu J, et al. Global mapping of H3K4me3 and H3K27me3 reveals specificity and plasticity in lineage fate determination of differentiating $\mathrm{CD}^{+} \mathrm{T}$ cells. Immunity 2009; 30: 155-167.

117 Zissel G. Cellular activation in the immune response of sarcoidosis. Semin Respir Crit Care Med 2014; 35: 307-315.

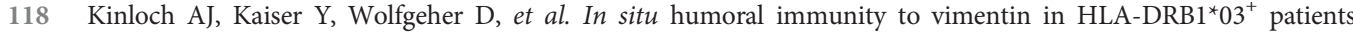
with pulmonary sarcoidosis. Front Immunol 2018; 9: 1516.

119 Parasa VR, Forsslund H, Enger T, et al. Enhanced CD8 ${ }^{+}$cytolytic T cell responses in the peripheral circulation of patients with sarcoidosis and non-Lofgren's disease. Respir Med 2017; 138S: S38-S44.

120 Rivera NV, Hagemann-Jensen M, Ferreira MAR, et al. Common variants of T-cells contribute differently to phenotypic variation in sarcoidosis. Sci Rep 2017; 7: 5623.

121 Kamphuis LS, van Zelm MC, Lam KH, et al. Perigranuloma localization and abnormal maturation of B cells: emerging key players in sarcoidosis? Am J Respir Crit Care Med 2013; 187: 406-416.

122 Hunninghake GW, Crystal RG. Mechanisms of hypergammaglobulinemia in pulmonary sarcoidosis. Site of increased antibody production and role of T lymphocytes. J Clin Invest 1981; 67: 86-92.

123 Heyder $\mathrm{T}$, Wiklundh E, Eklund $\mathrm{A}$, et al. Altered $\mathrm{FC}$ galactosylation in $\mathrm{IgG}_{4}$ is a potential serum marker for chronic lung disease. ERJ Open Res 2018; 4: 00033-2018.

124 Duhlin A, Chen Y, Wermeling F, et al. Selective memory to apoptotic cell-derived self-antigens with implications for systemic lupus erythematosus development. J Immunol 2016; 197: 2618-2626.

125 Onuora S. Autoimmunity: apoptotic cells induce immune memory. Nat Rev Rheumatol 2016; 12 : 559. 
126 Dørum S, Steinsbø O, Bergseng E, et al. Gluten-specific antibodies of celiac disease gut plasma cells recognize long proteolytic fragments that typically harbor T-cell epitopes. Sci Rep 2016; 6: 25565.

127 Mor-Vaknin N, Punturieri A, Sitwala K, et al. Vimentin is secreted by activated macrophages. Nat Cell Biol 2003; 5: 59-63.

128 Li FJ, Surolia R, Li H, et al. Autoimmunity to vimentin is associated with outcomes of patients with idiopathic pulmonary fibrosis. J Immunol 2017; 199: 1596-1605.

129 Mitchell AM, Kaiser Y, Falta MT, et al. Shared $\alpha \beta$ TCR usage in lungs of sarcoidosis patients with Löfgren's syndrome. J Immunol 2017; 199: 2279-2290.

130 Nagvekar N, Corlett L, Jacobson LW, et al. Scanning a DRB3 ${ }^{\star} 0101$ (DR52a)-restricted epitope cross-presented by DR3: overlapping natural and artificial determinants in the human acetylcholine receptor. J Immunol 1999; 162: 4079-4087.

131 Celada LJ, Kropski JA, Herazo-Maya JD, et al. PD-1 up-regulation on CD4 ${ }^{+} \mathrm{T}$ cells promotes pulmonary fibrosis through STAT3-mediated IL-17A and TGF- $\beta 1$ production. Sci Transl Med 2018; 10: eaar8356. 